\title{
Phylogenetic positions of Aeromonas encheleia, Aeromonas popoffii, Aeromonas DNA hybridization Group 11 and Aeromonas Group 501
}

\author{
Antonio J. Martínez-Murcia \\ Tel: +34 6590 3853. Fax: +346590 3965. e-mail: a.m.murcia@ua.es
}

Departamento de Biotecnología, Universidad de Alicante, Apartado 99, E-03080 Alicante, Spain

\begin{abstract}
The 165 rDNA sequences of the recently described Aeromonas encheleia and Aeromonas popoffii, were determined and compared with data from all known Aeromonas sp. Diagnostic 165 rDNA regions were also sequenced for some strains previously considered as an extension of $A$. encheleia and a strain of Aeromonas Group 501 (formerly Enteric Group 501). Results indicated that A. encheleia and A. popoffii are phylogenetically separated species as originally described. A conclusion about HG11 taxonomic status is not recommended until previous discrepancies are clarified by further DNA-DNA hybridization and sequencing studies.
\end{abstract}

Keywords: Aeromonas encheleia, Aeromonas popoffii, Aeromonas sp. HG11, Aeromonas Group 501, rRNA
The taxonomy of the genus Aeromonas has undergone major changes since its description in Bergey's Manual of Systematic Bacteriology (Popoff, 1984). Extensive DNA-DNA hybridization studies (Popoff et al., 1981; Hickman-Brenner et al., 1987, 1988; Kuijper et al., 1989; Carnahan et al., 1991b) have resulted in the recognition of fourteen so-called DNA homology groups (HG): Aeromonas hydrophila (HG1), Aeromonas sp. (unnamed HG2), Aeromonas salmonicida (HG3), Aeromonas caviae (HG4), Aeromonas media (HG5), Aeromonas eucrenophila (HG6), Aeromonas sobria (HG7), Aeromonas veronii biogroup sobria (HG8), Aeromonas jandaei (HG9), Aeromonas veronii biogroup veronii (HG10), Aeromonas sp. (unnamed; HG11), Aeromonas schubertii (HG12), Aeromonas Group 501 (HG13; formerly Enteric Group 501) and Aeromonas trota (HG14). The name Aeromonas bestiarum has been proposed for strains included in HG2 (Ali et al., 1996). Recently, three new descriptions of species include: Aeromonas allosaccharophila (Martínez-Murcia et al., 1992b), Aeromonas encheleia (Esteve et al., 1995) and Aeromonas popoffii (Huys et al., 1997b). Discrepancies remain between observed HGs and groups derived from phenotypic analysis. The species Aeromonas ichthiosmia (Schubert et al., 1990b) and Aeromonas enteropelogenes (Schubert

Abbreviation: HG, hybridization group. et al., 1990a) are now considered to be synonyms of $A$. veronii and $A$. trota, respectively, as they were identical by $16 \mathrm{~S}$ rDNA sequencing (Collins et al., 1993), phenotyping, fatty acid profile by gas liquid chromatography, and nearly identical by ribotyping (Carnahan, 1993). DNA probes and RFLP profiles designed from 16S rDNA diagnostic regions have served to identify most species of the genus Aeromonas (MartínezMurcia, 1993; Ash et al., 1993a, b; Dorsch et al., 1994; Khan \& Cerniglia, 1997; Borrell et al., 1997). A chemotaxonomic and genotypic study carried out by Huys et al. (1996a, b) have questioned the original species description of $A$. encheleia as some $A$. eucrenophila and Aeromonas sp. HG11 strains were affiliated to $A$. encheleia. Further, the inclusion of Aeromonas sp. HG11 in $A$. encheleia and extended descriptions of $A$. eucrenophila and $A$. encheleia were proposed (Huys et al., 1997a), which is in contrast to the original description based on phenotype and DNA-DNA pairing (Esteve et al., 1995). The 16S rDNA sequence of $A$. encheleia type strain (S181 ${ }^{\mathrm{T}}$, CECT $4342^{\mathrm{T}}$ ) was not included in either the original or the extended descriptions of $A$. encheleia (Esteve et al., 1995; Huys et al., 1997a). A phylogenetic analysis of all known Aeromonas spp., including $A$. encheleia, $A$. popoffii and Aeromonas Group 501 is reported in the present study.

The $A$. encheleia type strain (S181) was obtained in 1991 from Esteve's personal collection and later, a duplicate CECT $4342^{\mathrm{T}}$ and Aeromonas Group 501 


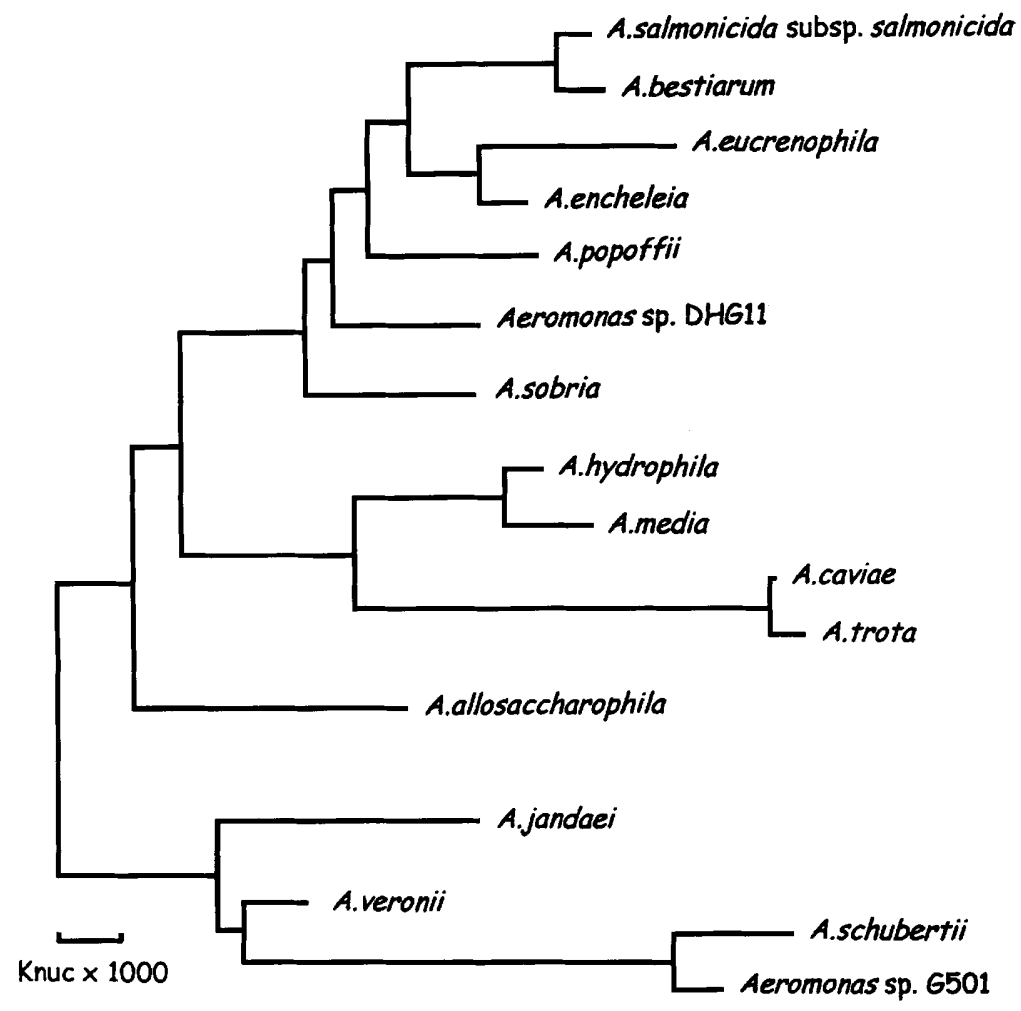

\begin{abstract}
Fig. 1. Phylogenetic relationships of described Aeromonas species (or DNA Homology Groups) as determined by a continuous 1502-nucleotide 165 rDNA sequence comparison using the neighbourjoining method. Strains and sequence accession numbers (in parentheses) are: Aeromonas hydrophila ATCC 7966', (X60404); A. bestiarum CIP 7430', (X60406); $A$. salmonicida NCIMB 1102', (X60405); $A$. caviae NCIMB $13016^{\top}$, (X60408); A. media ATCC 33907', (X60410); A. eucrenophila NCIMB $74^{\top}$, (X60411); $A$. sobria NCIMB $12065^{\top},(X 60412) ; A$ veronii ATCC 35624', (X60414); A. jandaei ATCC 49568 ${ }^{\top}$, (X60413); Aeromonas sp. DHG11 ATCC 35941' (X604417); A. schubertii ATCC 43700', (X60416); A. trota ATCC 49657', (X60415); A. allosaccharophila CECT 4199', (S39232); A. encheleia CECT 4342', (AJ224309); A. popoffii LMG 17541 ${ }^{\top}$, (AJ224308); Aeromonas Group 501 CECT 4254, (U88663).
\end{abstract}

strain CECT 4254 (ATCC 43946), from the Colección Española de Cultivos Tipo (CECT; Universidad de Valencia, Spain). All other strains, listed in Table 2, were provided in 1995 by M. Altwegg (Institute of Medical Microbiology, Zürich, Switzerland). Strain A. popoffi $\left(\mathrm{LMG} 17541^{\mathrm{T}}\right.$ ) was a gift from M. J. Figueras, Universidad Rovira i Virgili, Reus, Spain. Strains were cultivated in trypticase soy broth (Oxoid) at $30^{\circ} \mathrm{C}$ for $24 \mathrm{~h}$. Cultures were harvested and washed in deionized sterile water. Total DNA was extracted and purified, PCR performed and 16S rDNA sequence (continuous stretch of 1502 nucleotides) of $A$. encheleia CECT $4342^{\mathrm{T}}$ determined following the methods described in Martínez-Murcia et al. (1992a). The homologous sequence (1502 nucleotides) of $A$. popoffii LMG $17541^{\mathrm{T}}$ and the diagnostic 16S rDNA nucleotides located at the $\mathrm{V} 2$ and $\mathrm{V} 3$ regions (ca a continuous stretch of $300 \mathrm{bp}$ ranging from positions 230 to 530, approximately; Martínez-Murcia et al., 1992a) of the remaining strains (Table 2) were sequenced using the Cy5 AutoRead Sequencing Kit (Pharmacia) on the ALFexpress DNA sequencer (Pharmacia), according to the manufacturer's indications. After this work was completed, partial $16 \mathrm{~S}$ rRNAs of $A$. encheleia and $A$. popoffii (1407 nucleotides each) were found submitted in the GenBank in February 1998 by Demarta and co-workers (accession numbers AJ224309 and AJ224308, respectively). Except for size, sequences were compared and no difference was found. Newly determined sequences at both ends ( 95 nucleotides) of the gene were found to be conserved to all these known for Aeromonas. Sequences of A. encheleia, A. popoffii and Aeromonas Group
501, were aligned to other previously published sequences of Aeromonas (Martinez-Murcia et al., 1992a, b) and a phylogenetic tree produced by the neighbourjoining method (Saitou \& Nei, 1987) using the MEGA Program version 1.01 (Fig. 1).

The original description of $A$. schubertii was based on seven highly related strains with the vernacular name Enteric Group 501 (Hickman-Brenner et al., 1988). This group included an eighth strain, CDC 2478-85 (ATCC 43946), that was less related to $A$. schubertii by DNA hybridization $\left(70 \%\right.$ at $60^{\circ} \mathrm{C}, 61 \%$ at $75^{\circ} \mathrm{C}$, with a divergence of $5 \%$ ). This result and phenotype suggest that this strain is close to $A$. schubertii but has diverged somewhat and authors kept it, together with a new strain CDC 2555-87, in the so-called Aeromonas Group 501 (Hickman-Brenner et al., 1988). A specific HG number, HG13, was later assigned (Carnahan et al., 1991a). Sequencing of about $450 \mathrm{bp}$ of the $16 \mathrm{~S}$ rDNA 5'-end of strain CECT 4254 (CDC 2478-85) indicated a close relationship to $A$. schubertii but four nucleotide differences were detected. This stretch was compared with the sequence $(1467 \mathrm{nt})$ determined from the same strain and deposited by A. M. Whitney in the databases (accession no. U88663) in August 1997. Two inconsistencies were found: the sequence from the GeneBank showed variation at two positions (202 and 203; numbering as by Martínez-Murcia et al., 1992a) that are conserved for all Aeromonas (guanine at both sites). Further sequencing confirmed our previous result with no ambiguities. Excluding these two heterogeneities, the sequence $(1467 \mathrm{bp})$ of Aeromonas Group 501 was different from that of $A$. 
Table 1. Number of nucleotide differences in the 165 rDNA sequences of $A$. encheleia, $A$. popoffii and Aeromonas Group 501 compared to those from all other Aeromonas species

1, Aeromonas hydrophila; 2, A. bestiarum; 3, A. salmonicida; 4, A. caviae; 5, A. media 6, A. eucrenophila; 7, A. sobria; $8, A$. veronii; $9, A$. jandaei; 10 , Aeromonas sp. DNA homology group

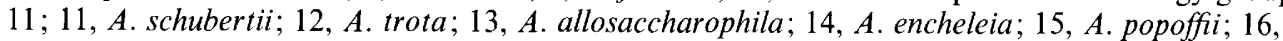
Aeromonas Group 501. Strains are listed in the legend to Fig. 1.

\begin{tabular}{|lrrrrrrrrrrrrrrrr|}
\hline Species & $\mathbf{1}$ & $\mathbf{2}$ & $\mathbf{3}$ & $\mathbf{4}$ & $\mathbf{5}$ & $\mathbf{6}$ & $\mathbf{7}$ & $\mathbf{8}$ & $\mathbf{9}$ & $\mathbf{1 0}$ & $\mathbf{1 1}$ & $\mathbf{1 2}$ & $\mathbf{1 3}$ & $\mathbf{1 4}$ & $\mathbf{1 5}$ & $\mathbf{1 6}$ \\
\hline A. encheleia & 11 & 7 & 5 & 25 & 14 & 6 & 10 & 17 & 24 & 8 & 28 & 26 & 17 & 0 & 7 & 30 \\
A. popoffi & 12 & 11 & 9 & 22 & 15 & 11 & 10 & 18 & 21 & 8 & 28 & 23 & 16 & 7 & 0 & 27 \\
$\begin{array}{l}\text { Aeromonas } \text { Group } \\
\text { 501 }\end{array}$ & 31 & 29 & 31 & 26 & 30 & 28 & 25 & 13 & 15 & 25 & 6 & 25 & 23 & 30 & 27 & 0 \\
\hline
\end{tabular}

schubertii only by six nucleotides. Present phylogenetic analysis indicated that this micro-organism may belong to a different Aeromonas sp., closely related to A. schubertii (Fig. 1), which is consistent with the relationship indicated by Hickman-Brenner et al. (1988) by DNA-DNA hybridization data.

Sequence comparison showed that the $16 \mathrm{~S}$ rDNA of $A$. popoffi is species-specific with an inter-species range of 7-28 nucleotide differences (Table 1). Description of this species (Huys et al., 1997b) indicated some resemblances with $A$. hydrophila (HG1), A. bestiarum (HG2) and $A$. salmonicida (HG3) on the basis of genotype and phenotype. The highest DNA-DNA hybridization values were determined with $A$. bestiarum (51-63\% ; Huys et al., 1997b). The 16S rDNA of $A$. popoffic exhibited a significant number of differences with the sequences of these three species (9-12 nucleotides); instead, the closest relative was $A$. encheleia (7 nucleotides) and Aeromonas sp. HG11 (8 nucleotides). The phylogenetic analysis (Fig. 1) indicates that $A$. popoffii belongs to a new phylogenetic line of descent within this genus, which supports the original description.

$A$. encheleia was more related to $A$. salmonicida and $A$. eucrenophila than to any other species on the basis of $16 \mathrm{~S}$ rDNA comparison (5 and 6 differences, respectively; Table 1). A close relationship to A. eucrenophila is supported by phenotype: most key phenotypic tests for the differentiation of all known Aeromonas spp. do not separate $A$. enchelia from $A$. eucrenophila (see Table 3 of Huys et al., 1997a, b). After alignment of all 16S rDNAs, the unnamed Aeromonas sp. HG11 exhibited a species-specific sequence including 'unique' nucleotides at two positions, i.e. a nucleotide composition at these sites only found in this species of the genus. The sequence of HG11 showed maximum similarity with that of $A$. sobria. Preliminarily, the tree of Fig. 1 and qualitative sequence analysis suggest the placement of HG11 as a single species phylogenetically separated from $A$. encheleia, according to previous data (Martínez-Murcia, 1993).

Diagnostic regions of the 16S rDNA (polymorphic sites at V2 and V3 regions; Martínez-Murcia et al., 1992a) of some $A$. eucrenophila and $A$. encheleia strains, considered to be a part of the A. encheleia extension (Huys et al., 1997a), were determined in the present work. The two known HG11 strains, A902 (a duplicate of ATCC 35941) and A926, showed the characteristic signature sequences of HG11, in agreement with published data (Martínez-Murcia et al., 1992a). In fact, both strains were peripheral to cluster II by AFLP (also called cluster A2; Huys et al., 1996a, b) and did not cluster to phenon 2 (Huys et al., 1997a), such a clustering considered as the $A$. encheleia extendedframe. Reported chromosomal DNA relatedness added more controversy: strain A902 (reference of HG11) shows $84 \%$ DNA-DNA similarity with the type strain of A. encheleia (Huys et al., 1997a), which is in marked disagreement to the $12 \%$ determined by Esteve et al. (1995). If the possibility of mislabelling or contamination of strains has been ruled out by performing experiments with duplicates from the original culture collections, this is one of the more serious discrepancies found in two sets of DNA-DNA hybridization values from different laboratories that used the same micro-organisms. Additional strains A9 and A1654, initially considered to be $A$. encheleia-like and $A$. eucrenophila, respectively, part of phenon 2 and grouped in cluster II of AFLP (Table 2), also showed the signature nucleotides of HG11. Relevant DNA-DNA hybridization values for strain A9, and the corresponding values for the pair A1654/HG11, were not reported (Huys et al., 1997a). Strain A1653 (A. eucrenophila), having shown a really high DNA-DNA hybridization value with HG11 $(96 \%$; Table 2), revealed the diagnostic nucleotides of $A$. encheleia. This result clearly represents a new case of conflict between these two approaches as these two taxa show separated phylogenetic lines. Two strains, A1655 and A1783, also showed the 16S rDNA nucleotides characteristic of $A$. encheleia, in agreement with the species assigned by Huys et al. (1997a). However, strains A1653, A1654 and A1655 were related to $A$. eucrenophila at a level of $80-82 \%$ DNA-DNA hybridization (Table 2; Schubert \& Hegazi, 1988) and, therefore, they were included in the original description of this species. These data make present controversy deeper. The determined sequences 
Table 2. Characteristics and classification based on $16 \mathrm{~S}$ rDNA signature sequences of some Aeromonas strains used in this study

LMG, BCCM/LMG Culture Collection, Laboratorium voor Microbiologie, Universiteit Gent, Ghent, Belgium. NR, Not reported.

\begin{tabular}{|c|c|c|c|c|c|c|c|}
\hline \multirow{2}{*}{$\begin{array}{l}\text { Formerly classified } \\
\text { as:* }\end{array}$} & \multirow[t]{2}{*}{ Strain (LMG) } & \multirow[t]{2}{*}{ Phenotype* } & \multirow[t]{2}{*}{ AFLP* } & \multicolumn{3}{|c|}{ DNA-DNA hybridization: ${ }^{*} \dagger$} & \multirow[t]{2}{*}{ Diagnostic $16 \mathrm{~S}$ rDNA } \\
\hline & & & & $\begin{array}{c}\text { A. } \\
\text { encheleia }\end{array}$ & $\begin{array}{c}\text { A. } \\
\text { eucrenophila }\end{array}$ & $\begin{array}{c}\text { Aeromonas } \\
\text { sp. HG11 }\end{array}$ & \\
\hline A. encheleia-like & A9 (16398) & Phenon 2 & Cluster II $\ddagger$ & NR & NR & NR & Aeromonas sp. HG11 \\
\hline Aeromonas sp. HG11 & $\mathrm{A} 902^{\mathrm{T}}\left(13075^{\mathrm{T}}\right)$ & Unclustered & Cluster II & $84(12)$ & 52 & 100 & Aeromonas sp. HG11 \\
\hline Aeromonas sp. HG11 & A926 (13076) & Unclustered & Cluster II & 87 & 51 & 94 & Aeromonas sp. HG11 \\
\hline A. eucrenophila & A1654 (13062) & Phenon 2 & Cluster II & 94 & $46(82)$ & NR & Aeromonas sp. HG11 \\
\hline A. eucrenophila & A1653 (13061) & Peripheric & Cluster II & 95 & $50(80)$ & 96 & A. encheleia \\
\hline A. eucrenophila & A1655 (13691) & Phenon 2 & Cluster II & NR & $50(80)$ & NR & A. encheleia \\
\hline A. encheleia-like & A1783 (16403) & Phenon 2 & Cluster II & NR & $\mathrm{NR}$ & NR & A. encheleia \\
\hline NR & A1784 (16404) & NR & NR & NR & NR & NR & A. eucrenophila \\
\hline A. encheleia-like & A1786 (16406) & Phenon 2 & Cluster II & NR & NR & NR & A. eucrenophila \\
\hline A. encheleia-like & A1782 (16402) & Phenon 2 & Cluster II & NR & NR & NR & $\begin{array}{c}\text { A. salmonicida/ } \\
\text { A. bestiarum }\end{array}$ \\
\hline
\end{tabular}

* Data from Huys et al. (1996a, b, 1997a).

+ Percentage DNA reassociated with type strains of respective species. Results in parentheses are from Esteve et al. (1995) and from Schubert \& Hegazi (1988).

$\ddagger$ Cluster II as determined by Huys et al. (1996b) corresponds to Cluster A2 of Huys et al. (1996a).

of strains A1784 and A1786 were characteristic of $A$. eucrenophila; however, that of strain A1782 was characteristic of $A$. salmonicida/A. bestiarum. These latter two species are only distinguishable by two paired nucleotides at positions 1011 and 1018 (Martinez-Murcia et al., 1992a), consistent with difficulties found in separating strains of $\mathrm{HG} 2 / \mathrm{HG} 3$ by DNA-DNA pairing (Hänninen, 1994). Again, DNA-DNA hybridizations have not been reported for the last three versus reference strains (Table 2). As some DNA-DNA hybridization values are unknown and, worthy of note, the thermal stability of reassociated DNA was not determined (see recommendation of Wayne et al., 1987), it is better to consider these, and similar strains, in need of urgent investigation.

Sequencing of $16 \mathrm{~S}$ rRNA is today considered a robust way to achieve bacterial taxonomy (Woese, 1987; Olsen et al., 1994) and DNA-DNA hybridization has been recommended for defining species (Wayne et al., 1987). Although in Aeromonas most rDNA derived relationships correlate well with DNA-DNA data, identical rRNA sequences but different species by DNA-DNA pairing have previously been detected (Martínez-Murcia et al., 1992a). In view of these conflicts, the results of DNA reassociation have always been taken as definitive (Collins et al., 1993) as the high overall conservation of the 16S rRNA may preclude the splitting of very closely related genotypes. However, at present, Aeromonas strains showing a DNA-DNA similarity range as high as $84-94 \%$ have never shown a phylogenetic divergence based on 8 nucleotide positions, two of which were HG11-specific composition. Although these polymorphisms are noticeable considering the tight phylogenetic depth of this genus, the number of nucleotide differences is too low and the possibility of molecular clock 'distortions' (i.e. plesiomorphy, inter-cistronic and inter-strain diversity, etc.) has to be taken into account. Consequently, and according to the previously reported limitations of $16 \mathrm{~S}$ rDNA analysis in the determination of relationships at the strain level (Stackebrandt \& Goebel, 1994), a conclusion about the HG11 taxonomic status should be taken on the basis of DNA-DNA hybridization data.

Bacterial species definition based on chromosomal DNA hybridization (Wayne et al., 1987) was empirically derived from a wide range of taxa, but values should not be treated as absolute or fixed. Concerns about variation on the level of DNA-DNA below which organisms are considered to belong to different species have been previously reported (Zakrzewska-Czerwinska et al., 1988). DNA-DNA pairing may give a 'too crude' measure of DNA sequence homology or, at least, not fine enough to split highly similar species. Grimont et al. (1980) showed that a relative binding ratio (RBR) of $70 \%$ obtained with the hydroxyapatite method corresponds, at optimal temperature, to about $55-60 \%$ RBR obtained with the $S_{1}$-nuclease method and this correlation may vary with the temperature. Discrepancies may be important when many RBRs in Aeromonas are bor- 
derline to the recommended value $(70 \%)$ to split species. The more pronounced lack of agreement so far reported is that for $A$. encheleia/HG11/ $A$. eucrenophila (Table 2) using the same reference strains but different hybridization methods: optical renaturation used by Huys et al. (1997a) and competitive nitrocellulose filter utilized by Esteve et al. (1995). Research on the correlation between several DNA-DNA procedures for these controversial strains is hereby suggested.

AFLP and ribotyping were added to support inclusion of HG11 in A. encheleia, commented in 'Letters to the Editor' of the International Journal of Systematic Bacteriology (Esteve, 1997). These grouping methods are based on fingerprints comprising chromosomal restriction fragments obtained from a limited (selected by availability) group of strains. Estimation of sizefingerprint resemblances and number of bona-fide strains included in each taxa might influence the final numerical analysis (Sneath \& Sokal, 1973). Currently, difficulties caused by low intensity/background ratios are also a source of error for fingerprint scoring. As patterns are highly heterogeneous and strain-specific, there is no doubt about their usefulness for bacterial typing and epidemiological studies (Vos et al., 1995). To date, however, the taxonomic value of the 'AFLP concept' (Huys et al., 1996b) and similar methods (e.g. those yielding some selected information about genomic organization of unknown evolutionary nature) in a wide range of bacterial taxa, is still to be demonstrated. If a phylogenetic frame is desired, knowledge about mode and extent to which genomic organization interrelates with, and reveals final stages of, bacterial species evolution, should be required.

In view of the $16 \mathrm{~S}$ rDNA results from the present study and all previously reported discrepancies between different sets of DNA-DNA hybridizations, a comprehensive study including all Aeromonas species (and HGs) is proposed by applying the same DNA-DNA hybridization method, sequencing of single $16 \mathrm{~S}$ and $23 \mathrm{~S} \mathrm{rDNA}$ copies of all operons of each strain, but also presumably faster molecular clocks as the $16 \mathrm{~S}-23 \mathrm{~S}$ rDNA spacers or 'house-keeping' protein coding genes. A sequencing project with the above aim is under way.

\section{ACKNOWLEDGEMENTS}

The 16S rDNA sequence of $A$. encheleia type strain, originally strain V181, was determined in 1991 while A.J.M.-M. was a PhD student at the IFR, Reading Laboratory, UK, under supervision of Dr M. D. Collins, who was of invaluable support.

\section{REFERENCES}

Ali, A., Carnahan, A. M., Altwegg, M., Lüthy-Hottenstein, J. \& Joseph, S. W. (1996). Aeromonas bestiarum sp. nov. (formerly genomospecies DNA group $2 \mathrm{~A}$. hydrophila), a new species isolated from non human sources. Med Microbiol Lett 5, $156-165$.
Ash, C., Martínez-Murcia, A. J. \& Collins, M. D. (1993a). Identification of Aeromonas schubertii and Aeromonas jandaei by using a polymerase chain reaction-probe test. FEMS Microbiol Lett 108, 151-156.

Ash, C., Martínez-Murcia, A. J. \& Collins, M. D. (1993b). Molecular identification of Aeromonas sobria by using a polymerase chain reaction-probe test. Med Microbiol Lett 2 , 80-86.

Borrell, N., Acinas, S. G., Figueras, M.-J. \& Martínez- Murcia, A. J. (1997). Identification of Aeromonas clinical isolates by restriction fragment length polymorphism of PCR-amplified $16 \mathrm{~S}$ rRNA genes. J Clin Microbiol 35, 1671-1674.

Carnahan, A. M. (1993). Aeromonas Taxonomy: a Sea of Change. 4th International Workshop on Aeromonas/Plesiomonas Atlanta, GA. Med Microbiol Newslett 2, 206-211.

Carnahan, A. M., Behram, S. \& Joseph, S. W. (1991a). Aerokey II : a flexible key for identifying clinical Aeromonas species. $J$ Clin Microbiol 29, 2843-2849.

Carnahan, A. M., Chakraborty, T., Fanning, G. R., Verma, D., Ali, A., Janda, J. M. \& Joseph, S. W. (1991b). Aeromonas trota sp. nov., an ampicillin-susceptible species isolated from clinical specimens. J Clin Microbiol 29, 1206-1210.

Collins, M. D., Martinez-Murcia, A. J. \& Cai, J. (1993). Aeromonas enteropelogenes and Aeromonas ichthiosmia are identical to Aeromonas trota and Aeromonas veronii, respectively, as revealed by small-subunit rRNA sequence analysis. Int $J$ Syst Bacteriol 43, 855-856.

Dorsch, M., Ashbolt, N. J., Cox, P. T. \& Goodman, A. E. (1994). Rapid identification of Aeromonas species using 16S rDNA targeted oligonucleotide primers: a molecular approach based on screening of environmental isolates. J Appl Bacteriol 77, $722-726$.

Esteve, C. (1997). Lett to the Editor. Is AFLP fingerprinting a true alternative to the DNA-DNA pairing method to assess genospecies in the genus Aeromonas? Int J Syst Bacteriol 47, 245-246.

Esteve, C., Gutiérrez, M. C. \& Ventosa, A. (1995). Aeromonas encheleia sp. nov., isolated from European eels. Int $J$ Syst Bacteriol 45, 462-466.

Grimont, P. A. D., Popoff, M. Y., Grimont, F., Coynault, C. \& Lemeling, M. (1980). Reproducibility and correlation study of three deoxyribonucleic acid hybridization procedures. Curr Microbiol 4, 325-330.

Hänninen, M.-L. (1994). Phenotypic characteristics of the three hybridization groups of Aeromonas hydrophila complex isolated from different sources. $J$ Appl Bacteriol 76, 455-462.

Hickman-Brenner, F. W., MacDonald, K. L., Steigerwalt, A. G., Fanning, G. R., Brenner, D. J. \& Farmer, J. J., III (1987). Aeromonas veronii, a new ornithine decarboxlase-positive species that may cause diarrhoea. J Clin Microbiol 25, 900-906.

Hickman-Brenner, F. W., Fanning, G. R., Arduino, M. J., Brenner, D. J. \& Farmer, J. J., III (1988). Aeromonas schubertii, a new mannitol-negative species found in human clinical specimens. $J$ Clin Microbiol 26, 156I-1564.

Huys, G., Altwegg, M., Hänninen, M.-L., Vancanneyt, M., Vauterin, L., Coopman, R., Torck, U., Lüthy-Hottenstein, J., Janssen, P. \& Kersters, K. (1996a). Genotypic and chemotaxonomic description of two subgroups in the species Aeromonas eucrenophila and their affiliation to $A$. encheleia and Aeromonas DNA hybridization group 11. Syst Appl Microbiol 19, 616-623.

Huys, G., Coopman, R., Janssen, P. \& Kersters, K. (1996b). High- 
resolution genotypic analysis of the genus Aeromonas by AFLP fingerprinting. Int $J$ Syst Bacteriol 46, 572-580.

Huys, G., Kampfer, P., Altwegg, M., Coopman, R., Janssen, P., Gillis, M. \& Kersters, K. (1997a). Inclusion of Aeromonas DNA hybridization Group 11 in Aeromonas encheleia and extended descriptions of the species Aeromonas eucrenophila and $A$. encheleia. Int J Syst Bacteriol 47, 1157-1164.

Huys, G., Kampfer, P., Altwegg, M., Kersters, I., Lamb, A., Coopman, R., Luthy-Hottenstein, J., Vancanneyt, M., Janssen, P. \& Kersters, K. (1997b). Aeromonas popoffii sp. nov., a mesophilic bacterium isolated from drinking water production plants and reservoirs. Int J Syst Bacteriol 47, 1165-1171.

Khan, A. A. \& Cerniglia, C. E. (1997). Rapid and sensitive method for the detection of Aeromonas caviae and Aeromonas trota by polymerase chain reaction. Lett Appl Microbiol 24, 233-239.

Kuijper, E. J., Steigerwalt, A. G., Schoenmakers, B. S. C. I. M., Peeters, M. F., Zanen, H. C. \& Brenner, D. J. (1989). Phenotypic characterization and DNA relatedness in human fecal isolates of Aeromonas species. J Clin Microbiol 27, 132-138.

Martínez-Murcia, A. J. (1993). Phylogenetic analysis of the genera Leuconostoc and Aeromonas. PhD thesis, University of Reading.

Martínez-Murcia, A. J., Benlloch, S. \& Collins, M. D. (1992a). Phylogenetic interrelationships of members of the genera Aeromonas and Plesiomonas as determined by $16 \mathrm{~S}$ ribosomal DNA sequencing: lack of congruence with results of DNADNA hybridizations. Int $J$ Syst Bacteriol 42, 412-421.

Martínez-Murcia, A. J., Esteve, C., Garay, E. \& Collins, M. D. (1992b). Aeromonas allosaccharophila sp. nov., a new mesophilic member of the genus Aeromonas. FEMS Microbiol Lett 91, 199-206.

Olsen, G. J., Woese, C. R. \& Overbeek, R. (1994). The winds of (evolutionary) change: breathing new life into microbiology. $J$ Bacteriol 176, 1-6.

Popoff, M. Y. (1984). Genus III Aeromonas. Kluyver and van Niel 1936, 398 . In Bergey's Manual of Systematic Bacteriology, vol 1, pp. 545-548. Edited by N. R. Krieg and J. E. Holt. Williams \& Wilkins.
Popoff, M. Y., Coynault, C., Kiredjian, M. \& Lemelin, M. (1981). Polynucleotide sequence relatedness among motile Aeromonas species. Curr Microbiol 5, 109-114.

Saitou, N. \& Nei, M. (1987). The neighbor-joining method: a new method for reconstructing phylogenetic trees. Mol Biol Evol 4, 406-425.

Schubert, R. H. W. \& Hegazi, M. (1988). Aeromonas eucrenophila species nova Aeromonas caviae a later and illegitimate synonym of Aeromonas punctata. Zentbl Bakteriol Parasitenkd Infektkrank Hyg Abt 1 Orig Reihe A 268, 34-39.

Schubert, R. H. W., Hegazi, M. \& Wahlig, W. (1990a). Aeromonas enteropelogenes species nova. Hyg Med 15, 471-472.

Schubert, R. H. W., Hegazi, M. \& Wahlig, W. (1990b). Aeromonas ichthiosmia species nova. Hyg Med 15, 477-479.

Sneath, P. H. A. \& Sokal, R. R. (1973). Numerical Taxonomy. The Principles and Practice of Numerical Classification. San Francisco: Freeman.

Stackebrandt, E. \& Goebel, B. M. (1994). A place for DNA-DNA reassociation and 16S rRNA sequence analysis in the present species definition in bacteriology. Int $J$ Syst Bacteriol 44, 846-849.

Vos, P., Hogers, R., Bleeker, M., Reijans, M., van de Lee, T., Hornes, M., Frijters, A., Pot, J., Peleman, J., Kuijper, M. \& Zabeau, M. (1995). AFLP ${ }^{\mathrm{TM}}$ : a new technique for DNA fingerprinting. Nucleic Acids Res 23, 4407-4414.

Wayne, L. G., Brenner, D. J., Colwell, R. R., Grimont, P. A. D., Kandler, O., Krichevsky, M. I., Moore, W. E. C., Murray, R. G. E., Stackebrandt, E., Starr, M. P. \& Trüper, H. G. (1987). International Committee on Systematic Bacteriology. Report of the ad hoc committee on reconciliation of approaches to bacterial systematics. Int J Syst Bacteriol 37, 463-464.

Woese, C. R. (1987). Bacterial evolution. Microbiol Rev 51, 221-271.

Zakrzewska-Czerwinska, J., Mordaski, M. \& Goodfellow, M. (1988). DNA base composition and homology values in the classification of some Rhodococcus species. J Gen Microbiol 134, 2807-2813. 